\title{
EVALUATION OF BREASTFEEDING IN A BABY-FRIENDLY CITY, ÇORUM, TURKEY
}

\author{
P. Elif Erkul', S. Songül Yalçın², Sevda Kılıç ${ }^{1}$ \\ ${ }^{1}$ Çorum Maternity Ward and Children Hospital, Çorum, Turkey \\ 2Hacettepe University, Faculty of Medicine, Department of Pediatrics, Ankara, Turkey
}

\begin{abstract}
SUMMARY
Corum is one of the Baby-F riendly Cities in Turkey since 2004. For optimum initiation and continuing of breastfeeding, not only educating the mothers about breast milk and breastfeeding is enough but also social support systems including family support is very important. The aim of this study was to evaluate the breast feeding status and the effect of lactation counseling support (LCS) on breastfeeding and social support in a Baby-Friendly City. In a cross-sectional study, a questionnaire was administered to 800 mothers of infants between 2-24 months admitted to government and private hospitals and government health facilities in urban part, towns and villages of Çorum for any reason, between February 2006 and February 2007. Mothers' and fathers' age and education level, the type of family, the sex and the order of children, the type of birth, the infants' birth weights, planned pregnancy did not affect the participation of LCS. Mothers who gave colostrum as the first food had more frequently taken LCS than mothers who gave prelacteal foods $(p<0.01)$. The percentage of LCS in mothers who knew the expression of breast milk and didn't give bottle feeding was higher compared to others (respectively; $p<0.01, p=0.05$ ). Mothers supported from husbands, sisters and mothersin-law participated more frequently $(p<0.05)$ in LCS than unsupported mothers. LCS is very important for mothers to develop correct attitudes and behavior about breastfeeding and family collaboration. Further regional studies should be done to follow the changes in breastfeeding status, to detect the local problems and to arrange special training programmes.
\end{abstract}

Key words: breastfeeding, baby-friendly city, lactation consultant education programme, social support

Address for correspondence: S. S. Yalçin, Unit of Social Pediatrics, Department of Pediatrics, Faculty of Medicine, Hacettepe University, 06100, Ankara, Turkey. E-mail: siyalcin@ hacettepe.edu.tr

\section{INTRODUCTION}

Breastfeeding is the unique source of nutrition that plays an important role in the growth, development and survival of infants (1). Since the 1990s WHO/UNICEF developed the "Baby-Friendly Hospital Initiative” with its “Ten Steps to Successful Breastfeeding' which includes early breastfeeding initiation, rooming-in, encourages breastfeeding on demand, gives no artificial teats or dummies to infants, gives newborn no food or milk other than breastmilk (2, 3). To achieve this goal, all mothers who are admitted to health facilities during their pregnancy and lactation periods should be encouraged to breast feed and given proper counseling about breastfeeding. In baby-friendly hospitals or health centers voluntary health personnel is trained about lactation consultation to realize these steps (4).

In Turkey, 'promotion of breast feeding and Baby-Friendly Hospital programme' has been conducted with the collaboration of Ministry of Health and UNICEF since 1991, synchronous with similar programmes in the world (5). Health care workers have been trained in "Lactation Counselor Certificate Programme (LCCP)" during theoretical and practical three days course to become lactation consultants. Then, lactation consultants try to assist mothers and babies in learning the art of breastfeeding in their antenatal, postnatal and child health clinics. Face-to-face education of mothers by lactation counsellors is defined as "Lac- tation Counselling Support (LCS)”. In addition to Baby-Friendly Hospital, Baby Friendly City programme has been carried out with National Breastfeeding Promotion Committe in Turkey since 2002. National Breastfeeding Promotion Committe with the $\mathrm{MoH}$ urges the cities to take appropriate measures to increase knowledge on current WHO/UNICEF guidelines on optimal infant feeding practices and lactation counselling skills among health professionals and to strengthen infant feeding counselling at the community level (mother-to-mother support groups, more lactation centres in the regions) and to take up Baby-Friendly City Initiative. To be awarded a Baby Friendly City by Ministry of Health, all maternity hospitals should be certified "BabyFriendly", more than $10 \%$ of primary health centers should be designated a baby-friendly maternity wards, and additional efforts have to include regulation of the marketing of breast milk substitutes by companies making baby formula in baby-friendly hospitals, development of facilities for breastfeeding in public, breastfeeding counseling and training courses for health workers, pharmacies, and mass media programmes. According to Turkish Ministry of Health Statistical Reports, 619 hospitals, 72 cities were designated as "Baby-Friendly City" and 91\% of births occurred in baby-friendly hospitals in 2007 (6).

Çorum has been one of the Baby-Friendly Cities in Turkey since 2004. However, there is no regional field study that evaluates the effect of Baby-Friendly Cities in the "Ten Steps to Success- 
ful Breastfeeding” status and the changes of breastfeeding habits in Baby-Friendly Cities. For optimum initiation and continuing of breastfeeding, not only educating the mothers about breast milk and breastfeeding is enough but also social support systems including family support is deemed as very important (7-10). However, there was no published study about the effect of Baby-Friendly Initiative on social support in family identified. The present study was aimed to evaluate the breast feeding status and the effect of LCS on breastfeeding status and social support in a Baby-Friendly City, Çorum.

\section{MATERIAL AND METHODS}

This cross-sectional study was conducted in Çorum located $240 \mathrm{~km}$ east of the capital of Turkey with permission by Çorum Maternity Ward and Children Hospital. Çorum's population is 500,000 with its towns and villages (11). Çorum city was Baby-Friendly City since October 2004. All five government hospitals and one private hospital and 15 of 85 primary health facilities were designated baby-friendly health centers in Çorum $(6,11)$. To renew education of health centers and to certify new health personnel, at least two health care personnel from these 6 hospitals and 85 primary health facilities applied to LCCP course in 2006. After course, two midwifes/nurses from each health center were asked to conduct ten interviews (five per one midwife/nurse) with a constructed questionnaire in their health center to evaluate the status of breastfeeding and local problems. Trained midwifes/nurses filled in the constructed questionnaire in their center within one month after course and voluntary mothers of infants aged 2-24 months who were admitted to government and private hospitals or health centers in urban part, towns and villages of Çorum, for child health supervision and vaccination, were included into the study, between February 2006 and February 2007.

The questionnaire's thirty seven questions divided in five sections were presented to mothers face to face. In the first part the questions concerned the mother (mother's age, health status, cigarette smoking, and any disease during pregnancy and after delivery, planned pregnancy, if pleased about the sex of the infant). The second part included the socio-demographic characteristics (mother's and father's education, mothers' job, type of family, living place, the number of children, interval between births, the time of taking infant identity card). The third part contained information about the infant's age, sex, birth weight, type of delivery, infant's health status at birth, hospitalization. The fourth part was about infant's nutrition (the first breastfeeding time, prelacteal food, the time of giving complementary nutrition, giving dummy or bottle feeding). The last part was dedicated to breastfeeding (if mother was pleased about breastfeeding, if she took LCS, if she had been informed about expression of breast milk, breastfeeding problems, breastfeeding intervals, one or two breasts at one sucking, one sucking duration, breastfeeding frequency per day, family support).

Statistical analyses were conducted with Statistical Package for Social Science (SPSS Inc., Chicago, IL, USA). Student-t test was used to compare means of continuous parameters, $\chi^{2}$ to compare proportions and Fisher's exact test was used when applicable. $\mathrm{P}$ values $<0.05$ were considered significant.

\section{RESULTS}

General characteristics: The study enrolled 800 voluntary mothers of infants between 2-24 months of age, however, information about education in respect of lactation was not found in 5 files and 795 files were therefore analyzed.

Mothers' mean age was 25.9 (16-44) years and fathers' mean age was 29.8 (19-55) years. Of all, 231 mothers (29.1\%) and 396 fathers $(50.0 \%)$ had an education level of 8 years or more. 640 of mothers (80.5\%) were housewife. Of families under study 418 (52.8\%) were simple family (Table 1$)$. Residence was villages in 353 (44.4\%) mothers, towns in 178 (22.4\%) and Çorum center in 264 (33.2\%).

Table 1. The socio-demographic characteristics and participation in lactation counseling support, Çorum

\begin{tabular}{|l|c|c|c|c|}
\hline & & \multicolumn{2}{|c|}{ Lactation counseling } & \multirow{2}{*}{ Total\# } \\
\hline & & No\& & Yes $\&$ & \\
\hline Maternal age, yrs & & $26.4 \pm 4.9$ & $25.7 \pm 4.8$ & $25.9 \pm 4.9$ \\
\hline Paternal age, yrs & & $30.1 \pm 5.4$ & $29.6 \pm 5.2$ & $29.8 \pm 5.2$ \\
\hline \multirow{3}{*}{ Maternal education, yrs } & $\geq 8$ & $67(29.0)$ & $164(71.0)$ & $231(29.1)$ \\
\cline { 2 - 4 } & $<8$ & $184(32.7)$ & $378(67.3)$ & $562(70.9)$ \\
\hline \multirow{3}{*}{ Paternal education, yrs } & $\geq 8$ & $113(28.5)$ & $283(71.5)$ & $396(50.0)$ \\
\cline { 2 - 4 } & $<8$ & $138(34.8)$ & $258(65.2)$ & $396(50.0)$ \\
\hline \multirow{3}{*}{ Family type } & simple & $137(32.8)$ & $281(67.2)$ & $418(52.8)$ \\
\cline { 2 - 4 } & extended & $114(30.5)$ & $260(69.5)$ & $374(47.2)$ \\
\hline \multirow{3}{*}{ Residence* } & urban & $103(39.0)$ & $161(61.0)$ & $264(33.2)$ \\
\cline { 2 - 4 } & town & $56(31.5)$ & $122(68.5)$ & $178(22.4)$ \\
\cline { 2 - 4 } & village & $93(26.3)$ & $260(73.7)$ & $353(44.4)$ \\
\hline Total & & $252(31.7)$ & $543(68.3)$ & 795 \\
\hline
\end{tabular}

${ }^{*} \mathrm{p}<0.01, \&$ percentage of row, \# percentage of column

Of all, 221 mothers (28.4\%) had health problems (11.9\% anemia, $7.3 \%$ goiter, $2.5 \%$ hypertension) prior to pregnancy. Overall, 285 (36.5\%) women had health problems during pregnancy (25\% anemia, $1.8 \%$ gestational diabetes mellitus, $7.9 \%$ hypertension, $18.2 \%$ urinary tract infection, $4.7 \%$ disease with fever). The mean frequency of antenatal care was 4.51. Also, 99 (12.5\%) mothers had some health problems during delivery. During pregnancy or lactation period, 57 (7.2\%) mothers smoked cigarettes (Table 2).

Overall, 410 (51.6\%) infants were males (Table 3). The mean birth weight of infants was 3,160 g (range: 700-5,500 g). 332 (41.8\%) were born as the first child and 599 (75.6\%) were from planned pregnancies (Table 2 and 3). Nearly half of parents took identity cards of infants in one week (50.3\%) after birth (Table 4). The birth interval was below 24 months in 77 (19.0\%) women. The mean age of the infants was $10.5 \pm 6.7$ months, 303 (38.1\%) were 12-24 months of age (Table 4). 292 (36.8\%) infants were hospitalized in different times prior to interview of parents. The causes of hospitalization were neonatal hyperbilirubinemia in 52 (6.5\%), lower respiratory tract infections in 157 (29.6\%), 
Table 2. The maternal characteristics and participation in lactation counseling support, Çorum

\begin{tabular}{|l|c|c|c|c|}
\hline & & \multicolumn{2}{|c|}{ Lactation counseling } & \multirow{2}{*}{ Total\# } \\
\hline \multirow{2}{*}{ Health problem prior to pregnancy } & & No\& & $144(65.2)$ & $221(28.4)$ \\
\cline { 2 - 5 } & present & $77(34.8)$ & $391(70.1)$ & $558(71.6)$ \\
\hline \multirow{2}{*}{ Maternal cigarette smoking } & absent & $167(29.9)$ & $41(71.9)$ & $57(7.2)$ \\
\cline { 2 - 5 } & present & $16(28.1)$ & $502(68.0)$ & $738(92.8)$ \\
\hline Frequency of antenatal care & absent & $236(32.0)$ & $4.41 \pm 3.67$ & $4.51 \pm 3.72$ \\
\hline Maternal health problem during & & $4.71 \pm 3.81$ & $65(65.7)$ & $99(12.5)$ \\
\hline \multirow{2}{*}{ delivery } & present & $34(34.3)$ & $478(68.7)$ & $696(87.5)$ \\
\hline \multirow{2}{*}{ Be pleased with child sex } & absent & $218(31.3)$ & $408(68.1)$ & $599(75.6)$ \\
\hline & yes & $191(31.9)$ & $133(68.9)$ & $193(24.4)$ \\
\hline Total & no & $60(31.1)$ & $515(68.4)$ & $753(95.2)$ \\
\cline { 2 - 5 } & yes & $238(31.6)$ & $25(65.8)$ & $38(4.8)$ \\
\hline
\end{tabular}

\& percentage of row, \# percentage of column

Table 3. The infant's sex, birth order, interval, delivery type, birth weight and participation in lactation counseling support, Çorum

\begin{tabular}{|c|c|c|c|c|}
\hline & & \multicolumn{2}{|c|}{ Lactation counseling } & \multirow{2}{*}{ Total\# } \\
\hline & & No\& & Yes\& & \\
\hline \multirow{2}{*}{ Sex } & male & $131(32.0)$ & $279(68.0)$ & $410(51.6)$ \\
\hline & female & $121(31.4)$ & $264(68.6)$ & $385(48.4)$ \\
\hline \multirow{2}{*}{ Birth order } & 1st child & $101(30.4)$ & $231(69.6)$ & $332(41.8)$ \\
\hline & 22nd child & $150(32.5)$ & $312(67.5)$ & $462(58.2)$ \\
\hline \multirow{2}{*}{ Birth interval* $(n=405)$} & $<24$ month & $33(42.9)$ & $44(57.1)$ & $77(19.0)$ \\
\hline & $\geq 24$ month & $95(29.0)$ & $233(71.0)$ & $328(81.0)$ \\
\hline \multirow{2}{*}{ Delivery type } & Caesarean section & $104(34.1)$ & $201(65.9)$ & $305(38.6)$ \\
\hline & normal vaginal & $147(30.2)$ & $339(69.8)$ & $486(61.4)$ \\
\hline Birth weight, $\mathrm{g}$ & & $3179 \pm 564$ & $3150 \pm 527$ & $3160 \pm 540$ \\
\hline \multirow{2}{*}{ Birth weight } & $<2,500 \mathrm{~g}$ & $19(32.2)$ & $40(67.8)$ & $59(8.1)$ \\
\hline & $\geq 2,500 \mathrm{~g}$ & $214(31.8)$ & $459(68.2)$ & $673(91.9)$ \\
\hline \multirow{2}{*}{ Be pleased with child sex } & yes & $238(31.6)$ & $515(68.4)$ & $753(95.2)$ \\
\hline & no & $13(34.2)$ & $25(65.8)$ & $38(4.8)$ \\
\hline Total & & $252(31.7)$ & $543(68.3)$ & 795 \\
\hline
\end{tabular}

${ }^{*} p<0.05$, \& percentage of row, \# percentage of column

diarrhea in 31 (3.9\%), hernia in 11 (1.4\%), fever in $10(1.3 \%)$, febrile convulsion in $9(1.1 \%)$ and urinary tract infection in 5 (0.6\%) infants.

Breastfeeding status: The first breastfeeding time was within half an hour after birth in 434 (54.6\%) infants and 743 (93.1\%) infants were breastfed within 24 hours after birth. Of all, 650 (83.9\%) women gave colostrum to their babies for the first food (Table 5) and 759 (96.0\%) mothers were agreeable to breastfeeding. Nearly half of the mothers (58.0\%) were informed about expression of breast milk (Table 5). Mothers were mostly guided for manual expression (54.1\%) by midwifes and nurses (45.3\%).
Breastfeeding problems were seen in 242 (30.4\%) mothers within the first week after delivery. These were insufficient breast milk in 167 (20.9\%) cases, infant's sucking problem in 38 (4.8\%) and breast problems in 27 (3.4\%) cases in the first week of lactation. During lactation period, 353 (44.4\%) women thought that their breast milk was insufficient. The reasons, put forward for insufficient breast milk, were small breasts in 49 (14.0\%), insufficient mother nutrition in 145 (41.3\%), infant's not frequent sucking in 58 (16.5\%), anxiety in 85 (24.3\%).

Of infants, 331 (41.6\%) were bottle-fed and pacifier was given to 327 (41.1\%) babies (Table 6). Other milk, formula or complementary foods beyond breast milk was given to 44 (5.5\%) infants 
Table 4. The infants' age, health problem, the date of getting identity card and participation in lactation counseling support, Çorum

\begin{tabular}{|c|c|c|c|c|}
\hline & & & & \\
\hline & & No\& & Yes\& & I0tal $\#$ \\
\hline & $2-5$ & $59(26.1)$ & $167(73.9)$ & $226(28.4)$ \\
\hline Age, month* & 6-11 & $73(27.4)$ & $193(72.6)$ & $266(33.5)$ \\
\hline & $12-24$ & $120(39.6)$ & $183(60.4)$ & $303(38.1)$ \\
\hline Infontch holth nollom & yes & $50(28.4)$ & $126(71.6)$ & $176(22.2)$ \\
\hline 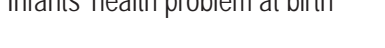 & no & $202(32.7)$ & $416(67.3)$ & $618(77.8)$ \\
\hline Any hospitalization during infancy & yes & $109(37.3)$ & $183(62.7)$ & $292(36.8)$ \\
\hline period* & no & $142(28.3)$ & $360(66.3)$ & $502(63.2)$ \\
\hline & $0-6$ & $117(29.3)$ & $283(70.7)$ & $400(50.3)$ \\
\hline Getting infant's identity card, post- & $7-29$ & $83(34.3)$ & $159(65.7)$ & $242(30.4)$ \\
\hline & $\geq 30$ & $52(34.0)$ & $101(66.0)$ & $153(19.2)$ \\
\hline Total & & $252(31.7)$ & $543(68.3)$ & 795 \\
\hline
\end{tabular}

$*_{p}<0.01$, \& percentage of row, \# percentage of column

Table 5. The breastfeeding characteristics and participation in lactation counseling support, Çorum

\begin{tabular}{|l|c|c|c|c|}
\hline & & \multicolumn{2}{|c|}{ Lactation counseling } & \multirow{2}{*}{ Total\# } \\
\hline \multirow{2}{*}{ Prelacteal food or water* } & & No\& & $73(58.4)$ & $125(16.1)$ \\
\hline \multirow{3}{*}{ Initiation of breastfeeding, hour } & yes & $52(41.6)$ & $455(70.0)$ & $650(83.9)$ \\
\cline { 2 - 5 } & no & $195(30.0)$ & $397(69.4)$ & $572(76.0)$ \\
\cline { 2 - 5 } & $2-5$ & $175(30.6)$ & $68(65.4)$ & $104(13.8)$ \\
\hline \multirow{3}{*}{ Mothers who prefer breastfeeding } & $\geq 6$ & $36(34.6)$ & $52(67.5)$ & $77(10.2)$ \\
\cline { 2 - 5 } & yes & $25(32.5)$ & $522(68.8)$ & $759(96.0)$ \\
\hline Frequency of breastfeeding/day & no & $13(40.6)$ & $19(59.4)$ & $32(4.0)$ \\
\hline Duration of breastfeeding, min** & $9.13 \pm 3.65$ & $13.34 \pm 3.60$ & $9.28 \pm 3.60$ \\
\hline $\begin{array}{l}\text { Given number of breasts at one } \\
\text { session }\end{array}$ & one & $76(34.1)$ & $147(65.9)$ & $12.7 \pm 7.3$ \\
\hline \multirow{2}{*}{$\begin{array}{l}\text { Maternal knowledge about breast } \\
\text { milk expression** }\end{array}$} & two & $152(30.1)$ & $353(69.9)$ & $223(30.6)$ \\
\hline Total & yes & $123(27.0)$ & $332(73.0)$ & $505(69.4)$ \\
\cline { 2 - 5 } & & $125(38.0)$ & $204(62.0)$ & $455(58.0)$ \\
\hline
\end{tabular}

${ }^{*} \mathrm{p}<0.05,{ }^{* *} \mathrm{p}<0.01, \&$ percentage of row, \# percentage of column

at 1 month. At the time of investigation, infants 2 months of age had taken other milk or formula in $23.9 \%$ and, this proportion was $37.0 \%$ in infants who were 3 months of age, $40.0 \%$ in infants who were 4 months of age, $51.2 \%$ in infants who were 5 months of age, $82.0 \%$ in infants who were 6 months of age and $97.9 \%$ in infants who were older than 6 months of age. The maternal reasons for beginning complementary foods were insufficient breast milk in 365 (45.8\%) cases, the right time for beginning in 228 (28.3\%) cases and to train baby to accept complementary foods in 28 (3.5\%) cases.
Breastfeeding counseling: Overall, 543 (68.3\%) mothers took LCS. The counselors were mostly midwifes-nurses (81.6\%). Villagers were interested in counseling more than urban dwellers $(p<0.01)$. The mothers' and fathers' ages and education levels, mothers' health status, mothers' diseases during prenatal, natal and postnatal period, the frequency of antenatal care, family type, mothers' smoking cigarette had no influence on the percentage of mothers who took the counseling (Table 1 and 2). Infants' sex, birth order, planned pregnancy, delivery type, birth weight, being pleased with baby's sex and age of registration for infant's 
Table 6. The presence of maternal counseling support for lactation according to the bottle-feeding, pacifier use and complementary feeding, Çorum

\begin{tabular}{|l|l|c|c|c|}
\hline & & \multicolumn{2}{|c|}{ Lactation counseling } & \multirow{2}{*}{ Total\# } \\
\hline \multirow{2}{*}{ Bottle-feeding* } & & No\& & Yes\& & $331(41.6)$ \\
\hline Age of bottle-feeding, month & presence & $120(36.3)$ & $211(63.7)$ & $464(58.4)$ \\
\cline { 2 - 5 } & absence & $132(28.4)$ & $332(71.6)$ & $4.73 \pm 3.22$ \\
\hline \multirow{2}{*}{ Pacifier use } & & $4.56 \pm 3.54$ & $4.84 \pm 3.02$ & $327(41.1)$ \\
\hline Starting age for pacifier, month & presence & $114(34.9)$ & $213(65.1)$ & $468(58.9)$ \\
\cline { 2 - 5 } & absence & $138(29.5)$ & $330(70.5)$ & $1.90 \pm 1.95$ \\
\hline Age of complementary feeding, month & & $1.94 \pm 2.29$ & $1.88 \pm 1.73$ & $5.26 \pm 2.40$ \\
\hline Total & & $5.12 \pm 2.42$ & $5.32 \pm 2.39$ & 795 \\
\hline
\end{tabular}

${ }^{*} \mathrm{p}<0.05, \&$ percentage of row, \# percentage of column

Table 7. Mothers taking postpartum social support by her relatives and participation in lactational counseling support, $n$ (\%), Çorum

\begin{tabular}{|l|l|c|c|c|c|c|c|c|c|}
\hline \multirow{2}{*}{ Support type } & \multirow{2}{*}{} & \multicolumn{2}{|c|}{ Husband } & \multicolumn{2}{c|}{ Mother } & \multicolumn{2}{c|}{ Mother-in-law } & \multicolumn{2}{c|}{ Sister } \\
\cline { 2 - 10 } & & Overall\# & Counseling $\&$ & Overall\# & Counseling $\&$ & Overall\# & Counseling $\&$ & Overall\# & Counseling $\&$ \\
\hline \multirow{2}{*}{ B reastfeeding } & yes & $498(63.2)$ & $353(70.9)^{*}$ & $449(57.0)$ & $313(69.7)$ & $469(59.5)$ & $336(71.6)^{*}$ & $228(29.0)$ & $173(75.9)^{* *}$ \\
\cline { 2 - 11 } & no & $290(36.8)$ & $185(63.8)$ & $339(43.0)$ & $225(66.4)$ & $319(40.5)$ & $202(63.3)$ & $558(71.0)$ & $364(65.2)$ \\
\hline \multirow{2}{*}{ Child care } & yes & $380(48.2)$ & $271(71.3)$ & $351(44.5)$ & $243(69.2)$ & $440(55.9)$ & $319(72.5)^{* *}$ & $153(19.4)$ & $120(78.4)^{* *}$ \\
\cline { 2 - 11 } & no & $408(51.8)$ & $267(65.4)$ & $437(55.5)$ & $295(67.5)$ & $347(44.1)$ & $219(63.1)$ & $634(80.6)$ & $417(65.8)$ \\
\hline \multirow{2}{*}{ Housework } & yes & $276(35.1)$ & $196(71.0)$ & $281(35.7)$ & $195(69.4)$ & $389(49.4)$ & $282(72.5)^{*}$ & $152(19.4)$ & $116(76.3)^{*}$ \\
\cline { 2 - 11 } & no & $511(64.9)$ & $341(66.7)$ & $507(64.3)$ & $343(67.7)$ & $398(50.6)$ & $255(64.1)$ & $631(80.6)$ & $418(66.2)$ \\
\hline
\end{tabular}

\# percentage of column, \& percentage of row

Presence of support compared to absence, ${ }^{*} \mathrm{p}<0.05,{ }^{* *} \mathrm{p}<0.01$

identity card did not change the percentage of mothers who took counseling. Mothers with birth interval below 24 months took counseling in $57.1 \%$, compared to $71.0 \%$ mothers with longer birth interval $(\mathrm{p}<0.05)$ (Table 3). Mothers of infants older than 12 months were less frequently trained compared to mothers of younger infants $(\mathrm{p}<0.01$, Table 4$)$. Mothers of hospitalized infants participated in LCS less than mothers of infants with no history of hospitalization (62.7\% and $66.3 \%$ respectively; $\mathrm{p}<0.01$, Table 4). The first breastfeeding time, breastfeeding frequency per day, interval between breastfeedings, one or two breasts at one sucking and if mother was pleasant to breastfeeding did not change with LCS. Mothers who gave colostrum had higher percentages for counseling than those who gave prelacteal foods as the first food after delivery (70.0\% and 58.4\% respectively; $\mathrm{p}<0.01$ ). Mothers who took LCS had longer sucking period than others (13.1 \pm 7.2 and 11.6 \pm 7.4 min respectively, $\mathrm{p}<0.01)$. Mothers who had some knowledge about breast pumping participated in LCS in 73.0\%, whilst, mothers with no knowledge took it in $62.0 \%(\mathrm{p}<0.01$, Table 5). The percentage of taking LCS in mothers complaining about breastfeeding problems was similar to mothers with no breastfeeding problems. The proportion of mothers practicing bottle-feeding was lower compared to those trained in lactation techniques $(\mathrm{p}<0.05)$, however, no difference in pacifier usage was observed (Table 6). Mean time for beginning complementary food did not changed with presence of LCS (Table 6).

Social support: Mothers whose breastfeeding was supported by their husbands, mothers-in-law and sisters participated in LCS more frequently (Table 7). Similarly, mothers, supported by their mothers-in-law and sisters for taking care of baby and housework, were trained more frequently. However, the proportion of mothers taking LCS was similar in all support type groups.

\section{DISCUSSION}

In our study, $68.3 \%$ of mothers reported that they had taken LCS. Among these mothers, the counselors were mostly midwifes and nurses (81.6\%) and doctors (11.0\%). The results of other studies that were done in Turkey were similar to our study and trained mothers' percentage was $76.1 \%$ in a group of 5,003 mothers and $62.4 \%$ in a group of 251 mothers (12, 13). In a prospective study in Athens, Greece, $34 \%$ of mothers were informed about the advantages of breastfeeding by health professionals and $42 \%$ were trained to breast-feed by the maternity nursing staff whereas $29 \%$ were not given any kind of information (14). 
In our study the number of trained mothers living in villages was very high compared with towns and city and that was explained by deployment of midwifes and nurses mostly in villages. In our city, LCS became more widespread in the last year of study; as a result, most of mothers were trained who gave birth during the last year.

In our study period, $16.1 \%$ of mothers gave prelacteal food in 2006-2007 compared to 40\% of mothers in national study in 2003 (15). Being Baby-Friendly City might cause this improvement in our city. Similar to our study, Ludvigsson reported that women who had received breastfeeding information from health care personnel avoided prelacteal food to a greater extent in Bolivia (16). Duong et al. reported that if a baby was fed colostrum after delivery, the likelihood for him/her to be exclusively breast-fed was substantially higher (17). Beginning life with colostrum as the first food protects against many infections and extends the duration of breastfeeding, also exclusive breastfeeding.

In our study LCS did not increase the mothers' breastfeeding in two hours after delivery. There are three possible explanations for this. One of the explanations is an increase in early initiation of breastfeeding in Turkey with BFH initiative in Turkey. In Turkey, breastfeeding was started within one hour in $20 \%$ of mothers in 1993, in 54\% of mothers in $2003(15,18)$. The second explanation is that breastfeeding education and support during prenatal care might not be appropriate. The same number of antenatal controls of trained and untrained mothers revealed that LCS in antenatal period was not applied appropriately. It was reported that obstetricians had significant deficits in knowledge of breastfeeding benefits and clinical management $(19,20)$. Therefore, we planned to train obstetrician in LCS. The third explanation is that brief breastfeeding messages might be given to mothers without taking into account their current needs $(21,22)$.

In present study mean time for beginning complementary foods was the same in mothers who had taken counseling and mothers who had not (5.32 and 5.12 months, respectively). Similarly, Çamurdan et al. reported that Baby-Friendly Hospital Initiative movement did not affect the time of weaning (23). Also Bonuck et al. observed similar rates of exclusive breastfeeding in the two groups and suggested that the intervention was not effective in helping women to breastfeed exclusively (24). Contrary to these studies, Kültürsay et al. and Neyzi et al. indicated that educating mothers about breastfeeding increased the time of exclusive breastfeeding $(25,26)$. So the effects of LCS on the time of complementary foods were controversial. These might be due to the absence of any educational material about complementary food in LCS.

Breastfeeding is traditional in Turkey and breastfeeding initiation rates are very high (97\%) and mean breastfeeding time is 14 months (6). In our country although the percentage of breast-feeding initiation is very high, median exclusive breastfeeding time is very low (one month). However, in our study although LCS did not alter mean exclusive breastfeeding time, our exclusive breastfeeding rate was high $(63.0 \%, 60.0 \%$ and $28.0 \%$ in infants who were three, four and six months of age, respectively, during investigation period). With these results, Çorum reached the proposed Healthy People 2010 goals of $63.0 \%$ of infants being exclusively breastfed at 3 months of age (27). In the other studies from Turkey exclusive breastfeeding rates were 34.3, 46, 53.7 and $60.9 \%$ at four months $(12,23,25,28)$. Another study from Norway reported exclusive breastfeeding rate as $44 \%$ at four months and $7 \%$ at six months of age (29).

Previous studies showed that breast pump use might have contributed to increased breastfeeding and duration and its intensity particularly in working mothers $(8,24)$. In our study, mothers who had the knowledge of breast milk expression were more frequently trained. Mostly midwife-nurses informed mothers about expression of breast milk.

In our study LCS did not decrease the pacifier usage in our region. However, only low proportion of mothers who use bottle feeding participated in LCS. In national study 36.6\% of infants under 6 months and $58.4 \%$ of infants $6-9$ months were given bottle-feeding in 2003 (15). Likely to our study, Matich et al. reported that educating mothers about breastfeeding together with social support decreased the usage of bottle-feeding (30). In another study from Turkey, it was revealed that introduction of bottle-feeding correlated with the discontinuation of breastfeeding (31). Lowering bottle-feeding decreases the risk of infections and extends the duration of breastfeeding, including exclusive breastfeeding. In this study, low percentage of maternal LCS training in hospitalized infants could be explained by high bottlefeeding and low frequency of colostrum at the beginning of life. Rishel et al. also showed that LCS decreased rates of infection and hospitalization (32).

In this study, mothers with long preceding birth interval had high frequency of taking LCS than those ones with short interval $(p<0.05)$. A possible explanation for this might be that mothers with long birth interval want to be trained more. Another aspect is that longer birth interval was shown to positively influence the breastfeeding duration in Bangladesh (33). Preceding birth interval is important not only for the child's health but also for mother's health. Multiple births close together deplete woman's body nutrients and increase the risk of giving birth to a low birth weight infant. Thus increasing the birth interval to two years or more would improve the health status of mother as well as breastfeeding duration (15).

Training of maternity ward staff and adoption of the BabyFriendly Hospital Initiative are successful interventions to encourage breastfeeding. Most mothers, if encouraged, given counseling, and protected from discouraging experiences and comments, could successfully breast-feed their infants for a long time $(34,35)$. Our results revealed that LCS increased the social support of family. The mothers who took advantage of LCS were significantly more supported by their husbands, sisters and mothers-in-law to breastfeed. Also they were more supported by their sisters and mothers-in-law in taking care of baby and housework. We found no published study about the effect of LCS on family support. On the other hand, in many studies, husbands', family members' (mothers, mothers-inlaw, sisters), friends', neighbours' and peer supports constituted positive effect on breastfeeding initiation and continuation (7, 8, $36,37)$. For successful and long duration of breastfeeding not only educating the mothers about breast milk and breastfeeding but also family support is very important.

As a result in Çorum, Step 3 (information of pregnant women about the benefits of breastfeeding) and Step 9 (giving no artificial teats or pacifiers to breastfed infants) were not adequately practiced in 2006-2007. Therefore, supportive training was planned for health care personnel. Breastfeeding peer counselors are used around the globe in varying situations and with varying degrees of success, 
primarily to increase breastfeeding duration and exclusivity among women from communities with low breastfeeding rates (38). The Breastfeeding Center at Çorum Maternity ward and Children Hospital has employed peer counselors since September 2007 to provide services to breastfeeding women in Çorum. Peer counseling programmes trained and employed women from the local community, who share the mother's social and cultural heritage.

In our study, mothers who had given colostrum for the first food after delivery, who had high frequency of knowledge about manual expression of breast milk and who had social support from family were found to participated in LCS in higher percentages in contrast to mothers who preferred bottle-feeding and mothers whose infants had a history of hospitalization. As a result, living in Baby-Friendly City and taking LCS helps mothers to develop correct attitudes and behavior about breastfeeding and family collaboration.

\section{Acknowledgement}

The authors would like to acknowledge the help of all midwifes-nurses who conducted the interviews and breastfeeding nurses, Nilgün Aktaş, Serpil Karakaş, Berna Doğan at Çorum Maternity ward and Children Hospital. Our thanks also go to Dr. Ferda Şirin and Dr. Serhat Cerit for their help in Lactation Counselor Certificate Program.

Ethical approval: This study was approved by Çorum Maternity ward and Children Hospital

\section{REFERENCES}

1. Horta BL, Bahl R, Martines JC, Victora CG. Evidence on the long-term effects of breastfeeding: systematic review and meta-analyses. Geneva: WHO; 2007.

2. World Health Organization. Evidence for the ten steps to succesful breastfeeding. WHO/CHD/98.9. Geneva: WHO; 1998

3. Philipp BL, Merewood A. The Baby-Friendly way: the best breastfeeding start. Pediatr Clin North Am. 2004 Jun;51(3):761-83.

4. World Health Organization. Protecting, promoting and supporting breast-feeding: the special role of maternity services. Geneva: WHO; 1989.

5. TC Ministry of Health. The report on status of children and women in Turkey: support for breast-feeding and program of baby friendly hospital initiative. Collaboration of Government of Turkey and UNICEF. Ankara: Turkish Ministry of Health; 2000. (In Turkish.)

6. General Directory of Mother and Child Health and Family Planning: statististical reports. Ankara: Turkish Ministry of Health; 2007.

7. Humphreys AS, Thomoson NJ, Miner KR. Intention to breastfeed in low-income pregnant women: the role of social support and previous experience. Birth. 1998 Sep;25(3):169-74.

8. Arora S, McJunkin C, Wehrer J, Kuhn P. Major factors influencing breastfeeding rates: mother's perception of father's attitude and milk supply. Pediatrics. 2000 Nov;106(5):E67.

9. Hoddinott P, Chalmers M, Pill R. One-to-one or group-based peer support for breastfeeding? Women's perceptions of a breastfeeding peer coaching intervention. Birth. 2006 Jun;33(2):139-46.

10. Raj VK, Plichta SB. The role of social support in breastfeeding promotion: a literature review. J Hum Lact. 1998 Mar;14(1):41-5.

11. Department Directory of Mother and Child Health and Family Planning: statistical data, Çorum Director of Health. Ankara: Turkish Ministry of Health; 2007. (In Turkish.)

12. Ünsal H, Atlihan F, Özkan H, Targan Ş, Hassoy H. The tendency to breastfeed in a certain population and influential factors. Çocuk Sağlığı ve Hastalıkları Dergisi. 2005;48:226-33. (In Turkish.)

13. Tunçel Kaynar E, Dündar C, Canbaz S, Peşken Y. Searching breastfeed status of children of 0-24 months applied to university hospital. C.Ü.Hemşirelik Yüksekokulu Dergisi. 2006;10:1-6. (In Turkish.)

14. Theofilogiannakou M, Skouroliakou M, Gounaris A, Panagiotakos D, Markantonis SL. Breast-feeding in Athens, Greece: factors associated with its initiation and duration. J Pediatr Gastroenterol Nutr. 2006 Sep;43(3):379-84.
15. Hacettepe University Institute of Population Studies, Macro International Inc. Turkish demographic and health survey 2003. Calverton: Macro International; 2004.

16. Ludvigsson JF. Breastfeeding in Bolivia - information and attitudes. BMC Pediatr. 2003 May 26;3:4

17. Duong DV, Binns CW, Lee AH. Breast-feeding initiation and exclusive breast-feeding in rural Vietnam. Public Health Nutr. 2004 Sep;7(6):795-9.

18. Hacettepe University Institute of Population Studies, Macro International Inc. Turkish demographic and health surveys 1993. Calverton: Macro International; 1994.

19. Power ML, Locke E, Chapin J, Klein L, Schulkin J. The effort to increase breast-feeding. Do obstetricians, in the forefront, need help? J Reprod Med. 2003 Feb;48(2):72-8.

20. Arora RS, Doherty C. Breast feeding and the Baby Friendly Initiative: is the training of doctors being ignored? Arch Dis Child. 2006 Dec;91(12):1044.

21. Serwint JR, Wilson ME, Vogelhut JW, Repke JT, Seidel HM. A randomized controlled trial of prenatal pediatric visits for urban, low-income families. Pediatrics. 1996 Dec;98(6 Pt 1):1069-75.

22. Greiner T, Mitra SN. Evaluation of the effect of a breastfeeding message integrated into a larger communication project. J Trop Pediatr. 1999 Dec;45(6):351-7.

23. Çamurdan AD, Özkan S, Yüksel D, Pasli F, Şahin F, Beyazova U. The effect of the baby-friendly hospital initiative on long-term breast feeding. Int J Clin Pract. 2007 Aug;61(8):1251-5.

24. Bonuck KA, Trombley M, Freeman K, McKee D. Randomized, controlled trial of a prenatal and postnatal lactation consultant intervention on duration and intensity of breastfeeding up to 12 months. Pediatrics. 2005 Dec;116(6):1413-26.

25. Neyzi O, Güleçyüz M, Dinçer Z, Olgun P, Kutluay T, Uzel N, et al. An educational intervention on promotion of breastfeeding complemented by continuing support. Paediatr Perinat Epidemiol. 1991 Jul;5(3):299-303.

26. Kültürsay N, Şen A, Kurugöl Z, Yenigün A. The factors affecting breastfeeding: increasing the period of breastfeeding without supplementation with education of mother. Turk Arch Ped. 1993;28:30-5.

27. U.S. Department of Health and Human Services. Healthy people 2010 conference edition. Vol. I, II. Washington, DC: U.S. Government Printing Office; 2000.

28. Kurugöl Z, Kusin N, Yenigün A, Özgür T. The epidemiology breastfeeding in İzmir. Turk Arch Ped. 1994;29:30-6.

29. Lande B, Andersen LF, Baerug A, Trygg KU, Lund-Larsen K, Veierød $\mathrm{MB}$, et al. Infant feeding practices and associated factors in first six months of life: the Norwegian infant nutrition survey. Acta Paediatr. 2003;92 (2):152-61.

30. Matich JR, Sims LS. A comparison of social support variables between women who intend to breast or bottle feed. Soc Sci Med. 1992 Apr;34(8):919-27.

31. Çamurdan AD, İlhan MN, Beyazova U, Şahin F, Vatandaş N, Eminoglu S. How to achieve long-term breast-feeding: factors associated with early discontinuation. Public Health Nutr. 2008 Nov;11(11):1173-9.

32. Rishel PE, Sweeney P. Comparison of breastfeeding rates among delivering infants in military treatment facilities with and without lactation consultants. Mil Med. 2005 May;170(5):435-8.

33. Giashuddin MS, Kabir M. Duration of breast-feeding in Bangladesh. Indian J Med Res. 2004 Jun;119(6):267-72.

34. Guise JM, Palda V, Westhoff C, Chan BK, Helfand M, Lieu TA; U.S Preventive Services Task Force. The effectiveness of primary care-based interventions to promote breastfeeding: systematic evidence review and meta-analysis for the US Preventive Services Task Force. Ann Fam Med. 2003 Jul-Aug;1(2):70-8.

35. Xu F, Binns C, Yu P, Bai Y. Determinants of breastfeeding initiation in Xinjiang, PR China, 2003-2004. Acta Paediatr. 2007 Feb;96(2):257-60.

36. Ingram J, Johnson D, Hamid N. South Asian grandmothers' influences on breastfeeding in Bristol. Midwifery. 2003 Dec;19(4):318-27.

37. Scott JA, Binns CW, Aroni RA. The influence of reported paternal attitudes on the decision to breast-feed. J Paediatr Child Health. 1997 Aug;33(4):305-7.

38. Merewood A, Philipp BL. Peer counselors for breastfeeding mothers in the hospital setting: trials, training, tributes, and tribulations. J Hum Lact. 2003 Feb;19(1):72-6.

Received March 2, 2009

Accepted in revised form September 1, 2009 